\title{
Propagação vegetativa de amoreira-preta das cultivares Tupy e BRS Cainguá
}

\author{
Vegetative propagation of blackberry of the cultivars Tupy and BRS Cainguá \\ Propagación vegetative de amoreira-preta de los cultivares Tupy y BRS Cainguá
}

Recebido: 21/03/2021 | Revisado: 26/03/2021 | Aceito: 29/03/2021 | Publicado: 09/04/2021

Claudia Farela Ribeiro Crosa

ORCID: https://orcid.org/0000-0002-5845-0157

Universidade Federal de Pelotas, Brasil

E-mail: crosa_claudia @yahoo.com.br

Rafaela Schmidt de Souza

ORCID: https://orcid.org/0000-0001-7009-3191 Universidade Federal de Pelotas, Brasil

E-mail: souzarafaela15@yahoo.com.br

Tatieli Silveira

ORCID: https://orcid.org/0000-0003-2211-0174

Universidade Federal de Pelotas, Brasil

E-mail: tatielisilveira@hotmail.com

Rudinei De Marco

ORCID: https://orcid.org/0000-0003-2648-0279

Universidade Federal de Pelotas, Brasil

E-mail: rudineidemarco@ hotmail.com

Luis Eduardo Correa Antunes

ORCID: https://orcid.org/0000-0002-0341-1476

Embrapa Clima Temperado, Brasil

E-mail: luis.antunes@embrapa.br

Carlos Roberto Martins

ORCID: https://orcid.org/0000-0001-8833-1629

Embrapa Clima Temperado, Brasil

E-mail: carlos.rmartins@embrapa.com

\begin{abstract}
Resumo
O presente trabalho teve como objetivo avaliar o potencial de enraizamento e brotação de estacas caulinares lenhosas e de raiz das cultivares Tupy e BRS Cainguá de amoreira-preta. Para a realização desse experimento foram coletadas estacas caulinares e radiculares das plantas matrizes de amoreira-preta. Posteriormente, essas estacas foram levadas para a casa de vegetação e colocadas em bandejas de poliestireno expandido (72 células) contendo mistura do substrato comercial Turfa fértil@ e vermiculita expandida na proporção 2:1 (v:v). Os tratamentos consistiram em diferentes tipos de estacas (caulinar e radicular) e duas cultivares ('Tupy' e 'Cainguá'). O delineamento experimental adotado foi inteiramente casualizados, sendo um bifatorial (cultivares X tipo de estaca) com quatro repetições, contendo 10 estacas cada. Após 97 dias da instalação do experimento foram avaliados os seguintes parâmetros: porcentagem de estacas enraizadas (\%), porcentagem de sobrevivência (\%), número de folhas, área foliar $\left(\mathrm{cm}^{2}\right)$, comprimento de parte aérea e da maior raiz $(\mathrm{cm})$, massa fresca e seca de parte aérea e do sistema radicular $(\mathrm{g})$. A propagação da amoreira-preta da cultivar BRS Cainguá pode ser realizada de forma eficaz tanto por estaca caulinar como radicular. No caso da cultivar Tupy teve menor potencial de enraizamento, quando comparada com a Cainguá. As estacas radiculares apresentaram maiores resultados no enraizamento de amoreira-preta.
\end{abstract}

Palavras-chaves: Multiplicação; Pequenas frutas; Rubus spp.

\begin{abstract}
The present work aimed to evaluate the rooting potential of stem and root cuttings in the blackberry crop with the cultivars Tupy and BRS Caingu. To carry out this experiment, woody cuttings and root cuttings of the blackberry mother plants were collected. These cuttings were then taken to the greenhouse and placed in expanded polystyrene trays (72 cells) containing a mixture of the commercial Turfa fértil@ substrate and expanded vermiculite in a 2: 1 (v: v) ratio. The treatments consisted of different types of cuttings (stem and root) and two cultivars ('Tupy' and ' BRS Cainguá'). The experimental design was completely randomized, being a bifactorial (cultivars X type of cutting) with four replications, containing 10 cuttings each. After 97 days of experiment installation, the following parameters were evaluated: percentage of rooted cuttings (\%), percentage of survival (\%), number of leaves, leaf area $\left(\mathrm{cm}^{2}\right)$, shoot length and the largest root $(\mathrm{cm})$, fresh and dry mass, and aerial and root system $(\mathrm{g})$. The propagation of $\mathrm{cv}$. BRS Cainguá can be performed effectively either by stem or root cut. In the case of cultivar Tupy, it had lower rooting potential when
\end{abstract}


compared to 'BRS Cainguá'. Root cuttings showed higher results in blackberry rooting.

Keywords: Stem cuttings; Root cuttings; Small fruits; Rubus spp.

\begin{abstract}
Resumen
El presente trabajo tuvo como objetivo evaluar el potencial de enraizamiento de esquejes de tallo y raíz en el cultivo de mora con los cultivares Tupy y BRS Caingu. Para llevar a cabo este experimento, se recolectaron esquejes leñosos y esquejes de raíces de las plantas madre de mora. Estos esquejes se llevaron luego al invernadero y se colocaron en bandejas de poliestireno expandido (72 celdas) que contenían una mezcla del sustrato comercial Turfa fertilß y vermiculita expandida en una proporción de 2: $1(\mathrm{v}: \mathrm{v})$. Los tratamientos consistieron en diferentes tipos de esquejes (tallo y raíz) y dos cultivares ('Tupy' y 'BRS Cainguá'). El diseño experimental fue completamente al azar, siendo bifactorial (cultivares X tipo de esqueje) con cuatro repeticiones, conteniendo 10 esquejes cada una. Luego de 97 días de instalación del experimento, se evaluaron los siguientes parámetros: porcentaje de esquejes enraizados (\%), porcentaje de supervivencia $(\%)$, número de hojas, área foliar $\left(\mathrm{cm}^{2}\right)$, longitud del brote y raíz más grande $(\mathrm{cm})$, fresca y masa seca, sistema aéreo y radicular (g). La propagación del cv. El BRS Cainguá se puede realizar eficazmente ya sea mediante corte de tallo o raíz. En el caso del cultivar Tupy, tuvo menor potencial de enraizamiento en comparación con 'BRS Cainguá'. Los esquejes de raíz mostraron resultados más altos en el enraizamiento de moras.
\end{abstract}

Palabras clave: Multiplicación; Frutos pequeños; Rubus spp.

\title{
1. Introdução
}

A produção brasileira das principais espécies de pequenas frutas como mirtilo (Vaccinium spp.), framboesa (Rubus ideaus) e amora-preta (Rubus spp.), são insuficientes para atender a demanda interna de comercialização, o que gera uma maior taxa de importação destas frutas que poderiam ser produzidos no país. Essas culturas estão entre as que apresentam boas perspectivas de ampliação do cultivo e geração de renda em áreas de agricultura familiar, em função da necessidade de uso intensivo de mão-de-obra e baixo índice de mecanização. Além disso, outro aspecto relevante seria a aceitação do mercado consumidor, devido às suas propriedades nutracêuticas (Antunes, 2002; Yamamoto, et al., 2013).

A 'Tupy' é considerada umas das cultivares de amoreira-preta mais plantadas no Brasil. Essa cultivar é oriunda dos cruzamentos realizados entre 'Uruguai' e a cultivar Comanche, realizado em 1982. As frutas são de coloração preta brilhante (ponto de colheita), firmes e apresentam um saber equilibrado entre a acidez e o açúcar (Antunes, 2002; Antunes, et al., 2004). A cultivar BRS Cainguá é derivada de um cruzamento realizado em 2004, na Embrapa Clima Temperado, localizada em Pelotas (Rio Grande do Sul), entre a Seleção 2/96 progenitora e a cultivar Caingangue (doadora de pólen). As frutas da 'BRS Cainguá' possuem sabor agradável para o mercado de produtos frescos. A firmeza e o brilho das frutas são médios e o tamanho é maior que o da cultivar Tupy (Raseira, et al., 2020).

Para a propagação vegetativa dessa frutífera podem ser usadas estacas herbáceas, semilenhosas e lenhosas, estacas de raízes, rebentos e cultura de tecidos. Todavia, a propagação por estaquia de raízes apresenta como desvantagem o número limitado de mudas, além do trabalho requerido para a obtenção das estacas (Beyl \& Trigiano, 2008; Yamamoto, et al., 2013).

O emprego de estacas caulinares na propagação da amoreira-preta é uma prática que tem sido utilizada, visto que, durante o período de dormência, em virtude da poda, obtém-se grande quantidade de ramos que podem ser utilizados na propagação por meio de estacas. Além disso, pode maximizar a utilização do material vegetal e não apenas eliminá-lo (Antunes, et al., 2000; Antunes \& Raseira, 2004; Andrade, et al., 2007).

Um dos fatores que predizem a produtividade e qualidade de frutas está na adoção de mudas de qualidade. Com isso, a escolha de métodos e formas de propagação é de suma importância para que as mudas apresentem desenvolvimento satisfatório (Franzon, et al., 2010).

Questões constantes dos produtores de frutas por mudas de alta qualidade fitossanitária, com uniformidade, que propiciem rendimentos em produtividade e na qualidade da fruta, exigem o desenvolvimento de novas tecnologias e produtos, além do refinamento das práticas de cultivo. As técnicas de propagação assumem grande importância na formação da muda de amoreira-preta (Dias \& Ono, 2010; Franzon, et al., 2010).

Desta forma, o objetivo foi avaliar o potencial de enraizamento e brotação de estacas caulinares e radiculares na cultura 
da amoreira-preta em duas cultivares Tupy e BRS Cainguá.

\section{Metodologia}

O experimento foi conduzido em casa de vegetação na Embrapa Clima Temperado (sede), localizada no município de Pelotas-RS, com as seguintes coordenadas geográficas: latitude $31^{\circ} 40^{\prime} 53.16^{\prime \prime} \mathrm{S}$ e longitude52²6'23.60"W.

Os tratamentos consistiam em diferentes tipos de estacas, uma lenhosa e outra de raízes, para a produção de mudas das cultivares de amoreira-preta 'Tupy' e a 'BRS Cainguá' (Figura 1).

Figura 1. Estacas de raízes (1A) e estacas caulinares (1B) de amora-preta, das cultivares 'Tupy' e 'BRS Cainguá', em bandejas de poliestireno, em casa de vegetação da Embrapa Clima Temperado.
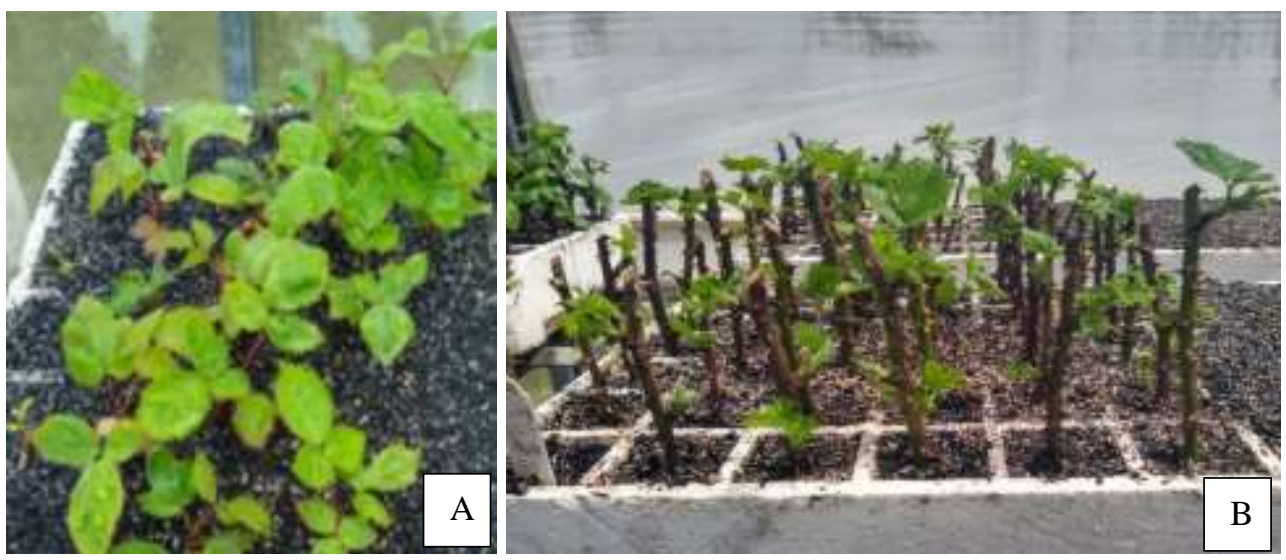

Fonte: Souza, R. S. Pelotas (2019).

As estacas caulinares e de raiz foram coletadas no início do mês de setembro das plantas matrizes de amoreira-preta. Posteriormente, as estacas foram padronizadas adotando para as estacas caulinares um comprimento de $15 \mathrm{~cm}$ e o diâmetro médio de $9 \mathrm{~mm}$, retiradas da parte mediana do ramo das plantas. Enquanto, que as estacas coletadas do sistema radicular, apresentavam comprimento de $4 \mathrm{~cm}$ e o diâmetro de $3 \mathrm{~mm}$. Essas estacas foram colocadas em bandejas de poliestireno expandido (72 células- 121,2 cm³), contendo uma mistura de Turfa fértil@ e vermiculita expandida na proporção 2:1 (v:v). As bandejas ficaram suspensas em bancadas em casa de vegetação, utilizou-se um sistema de irrigação por nebulização.

A irrigação foi programada da seguinte forma: ligar por 10 segundos a cada 15 minutos durante uma hora, o intervalo de funcionamento do sistema era a cada 2 horas. O sistema de irrigação era realizado na parte da manhã e à tarde, desligando durante a noite. Em dias nublados a irrigação era reprogramada, evitando o excesso de água nas bandejas.

O delineamento experimental adotado foi inteiramente casualizados, sendo um bifatorial (cultivares X tipo de estaca) com quatro repetições, contendo 10 estacas cada. Após 97 dias, avaliaram-se: porcentagem de estacas enraizadas (\%), número de folhas, comprimento de parte aérea e radicular $(\mathrm{cm})$, área foliar $\left(\mathrm{cm}^{2}\right)$, massa fresca e seca de parte aérea e radicular $(\mathrm{g})$.

O comprimento de parte aérea e da maior raiz foi mensurado com auxílio de régua graduada. Para a determinação dos parâmetros massa fresca e seca utilizou-se uma balança digital com precisão de $0,01 \mathrm{~g}$. A secagem do material vegetal foi feita em estufa de circulação de ar forçado a temperatura de $65^{\circ} \mathrm{C}$ até o peso constante. Para a obtenção da área foliar das plantas teve-se o auxílio de um integrador de área foliar modelo LI-COR $®(\mathrm{Li}-300 \mathrm{C}$ área meter).

Os dados das variáveis analisadas foram submetidos à análise de variância (ANOVA). No caso de significância, as médias foram comparadas pelo teste Tukey a 5\% de probabilidade de erro, utilizando o programa estatístico Genes (Cruz, 2013). 


\section{Resultados e Discussão}

Foram constatadas interações significativas $(\mathrm{p} \leq 0,05)$ para as variáveis, estacas enraizadas, comprimento de raiz $(\mathrm{CR}) \mathrm{e}$ área foliar (AF) das avaliações de estacas de parte aérea (PA) de ambas as cultivares. Para as demais variáveis não foi observada diferenças significativas (Tabela 1), bem como para a porcentagem de sobrevivência, sendo de 75\% para estacas de parte aérea e $100 \%$ para as estacas de raiz, para a cultivar Tupy e de $100 \%$ para as estacas de parte aérea e $97,5 \%$ para as estacas de raiz, para a cultivar BRS Cainguá (Tabela 2).

Tabela 1. Estacas enraizadas, Comprimento da Parte aérea (CPA) em cm, Comprimento da maior raiz (CR) em cm, Número de folhas (NF), Área foliar (AF) em $\mathrm{cm}^{3}$, Massa fresca da parte aérea (MFPA) em g, massa fresca de raiz (MFR) em g, massa seca de parte aérea (MSPA) em g e massa seca de raiz (MSR) em g, de estacas caulinares (E.C) e estacas de raiz das cultivares de amoreira- preta: Tupy e BRS Cainguá. Pelotas, RS, Brasil, 2019.

\begin{tabular}{|c|c|c|c|c|c|c|c|c|c|}
\hline \multirow[t]{2}{*}{ Cultivar } & \multicolumn{2}{|c|}{$\begin{array}{c}\text { Estacas } \\
\text { enraizadas (\%) }\end{array}$} & \multicolumn{2}{|c|}{$\begin{array}{l}\text { Comprimento de } \\
\text { parte aérea } \\
\text { (cm) }\end{array}$} & \multicolumn{2}{|c|}{$\begin{array}{l}\text { Comprimento } \\
\text { da maior raiz } \\
(\mathrm{cm})\end{array}$} & \multicolumn{2}{|c|}{$\begin{array}{l}\text { Número de } \\
\text { folhas }\end{array}$} & $\begin{array}{c}\text { Área foliar } \\
(\mathrm{cm}) \\
\end{array}$ \\
\hline & E.C. & E.R. & E.C & E.R. & E.C. & E.R. & E.C. & E.R & E.C. $\quad$ E.R. \\
\hline Tupy & $53,33 \mathrm{Bb}$ & $77,50 \mathrm{Ab}$ & $17,91 \mathrm{Aa}$ & $5,09 \mathrm{Bb}$ & $6,64 \mathrm{Bb}$ & 9,71Aa & 3Aa & $4 \mathrm{Aa}$ & $16,70 \mathrm{Ab} 9,27 \mathrm{Ab}$ \\
\hline BRS Cainguá & $82,50 \mathrm{Aa}$ & $97,50 \mathrm{Aa}$ & $22,28 \mathrm{Aa}$ & $10,66 \mathrm{Ba}$ & $9,16 \mathrm{Aa}$ & $14,02 \mathrm{Aa}$ & 3Aa & $5 \mathrm{Aa}$ & 32,07Aa 35,39Aa \\
\hline Cultivar & $\begin{array}{r}\text { Massa fi } \\
\text { parte } \\
\end{array}$ & $\begin{array}{l}\text { resca da } \\
\text { aérea } \\
\text { g) }\end{array}$ & $\begin{array}{r}\text { Massa } \mathrm{f} \\
\mathrm{ra} \\
(\varepsilon\end{array}$ & $\begin{array}{l}\text { resca de } \\
\text { aiz } \\
\text { ) }\end{array}$ & $\begin{array}{r}\text { Massa } \\
\text { parte } \\
(\end{array}$ & $\begin{array}{l}\text { seca de } \\
\text { aérea } \\
\text { g) }\end{array}$ & Mass & $\begin{array}{l}\text { seca de } \\
\text { aiz } \\
\text { g) }\end{array}$ & \\
\hline Tupy & $\begin{array}{l}\text { E.C. } \\
\text { 6,32Aa }\end{array}$ & $\begin{array}{c}\text { E.R. } \\
\text { 0,46Aa }\end{array}$ & $\begin{array}{l}\text { E.C. } \\
1,0 \mathrm{Aa}\end{array}$ & $\begin{array}{c}\text { E.R. } \\
1,25 \mathrm{Aa}\end{array}$ & $\begin{array}{c}\text { E.C. } \\
2,83 \mathrm{Aa}\end{array}$ & $\begin{array}{c}\text { E.R. } \\
\text { 0,09Aa }\end{array}$ & $\begin{array}{r}\text { E.C. } \\
0,16 A\end{array}$ & $\begin{array}{c}\text { E.R. } \\
0,37 \mathrm{Aa}\end{array}$ & \\
\hline BRS Cainguá & 7,94Ba & $0,64 \mathrm{Aa}$ & $0,78 \mathrm{Aa}$ & $1,0 \mathrm{Aa}$ & 3,60Aa & 0,33Aa & $0,25 \mathrm{~A}$ & $0,52 \mathrm{Aa}$ & \\
\hline
\end{tabular}

*Médias seguidas pela mesma letra minúscula na coluna e maiúscula na linha não diferem estatisticamente entre si ( $\mathrm{p} \leq 0,05)$. Fonte: Autores.

Tabela 2. Porcentagem de sobrevivência de estacas de raiz e parte aérea de amoreira- preta Tupy e BRS Cainguá. Pelotas, RS, Brasil, 2019.

\begin{tabular}{ccc}
\hline Cultivar & \multicolumn{2}{c}{ Porcentagem de sobrevivência (\%) } \\
\hline 'Tupy' & Estacas de parte aérea & Estacas de raiz \\
'BRS Cainguá' & 75 & 100 \\
& 100 & 97,5 \\
\hline
\end{tabular}

Fonte: Autores.

A sobrevivência das estacas está relacionada as reservas que foram acumuladas antes do período de enraizamento (Fachinello, et al., 2005), uma vez que essas reservas sejam mais abundantes associam-se com os maiores percentuais de enraizamento e sobrevivência.

A porcentagem de estacas enraizadas variou entre as cultivares, havendo diferenças significativas para a estaca caulinar (E. C.). A cv. Tupy teve menor porcentagem de enraizamento (53,33\%) quando comparada com a cv. BRS Cainguá, com 82,5\%. As estacas de raiz mostraram-se com maior potencial de enraizamento quando comparadas com as estacas caulinares (Tabela 1), apresentando maiores porcentagens (77,5\% para cv. Tupy ę $97,5 \%$ para a cv. BRS Cainguá). De maneira geral, a cv. BRS 
Cainguá apresentou maior potencial de enraizamento.

Quando avaliado o enraizamento de estacas de amoreira-preta, Andrade et al. (2007), com uso de diferentes concentrações de AIB, observaram 83\% de sobrevivência de estacas no tratamento sem AIB para a cultivar Tupy. Já, Vignolo et al. (2014), utilizando a mesma cultivar encontrou 97\% de sobrevivência das estacas, e sem uso de regulador, como feito neste estudo. Com uso de AIB, Antunes et al. (2000), encontraram uma porcentagem de 93,7 de enraizamento da cv Tupy. Em estudo sobre enraizamento de estacas caulinares de cv. Xavante, em diferentes substratos e aplicação de ácido indolbutírico (AIB) sobre estacas enraizadas foi obtido um percentual de 86,2. No entanto, a porcentagem de sobrevivência foi maior na ausência da aplicação do AIB (94,3\%) (Yamamoto, et al., 2013).

Foram observadas diferenças significativas no comprimento da parte aérea de estacas de raízes (p=0,05) e na área foliar (AF) $(\mathrm{p}=0,04)$, sendo observado valores maiores para a cv. BRS Cainguá, nas variáveis citadas acima, apresentaram os respectivos valores médios de 10,66 cm e 35,39 cm (Tabela 1). No entanto, a brotação foi mais lenta em estacas de raízes.

A cultivar BRS Cainguá apesar de ter características similares a da Tupy, por exemplo, a sua faixa de adaptação de áreas de 200 a 300 horas de acúmulo hibernal (temperaturas iguais ou menores que $7,2^{\circ} \mathrm{C}$ ), porém sua produção de frutas é menor em Kg, quando comparada a cv. Tupy no período de 2013 a 2017 (Antunes \& Raseira, 2018).

A cultivar Tupy para a variável CPA, em estacas caulinares apresentou maior média $(17,91 \mathrm{~cm})$ do que para estacas de raízes $(5,09 \mathrm{~cm})$, diferindo assim, significativamente. Também foi observado maior comprimento de raiz em estacas de raízes $(9,71 \mathrm{~cm})$, diferindo das estacas caulinar $(\mathrm{p}=0,04)$. No entanto, em estudo realizado por Torchelsen et al. (2012) estacas caulinares da cv. 'Tupy' obtiveram baixo índice de enraizamento.

Para a variável comprimento da maior raiz, foi observada a superioridade da cultivar BRS Cainguá em ambos os tipos de estacas $(\mathrm{PA}=9,16$ e $\mathrm{R}=14,07)$. Antunes et al. (2000), também observaram o menor comprimento na cultivar Tupy, quando comparado com outras cultivares, como as cultivares Brazos e Guarani. Entretanto, as conclusões são diferentes nos variados estudos, informando que fatores como, potencial genético de enraizamento da planta, condições fisiológicas da planta matriz, época de coleta, tipo de substrato e ambiente utilizado no enraizamento, entre outros estejam associados ao processo de formação e crescimento das raízes (Yamamoto, et al., 2013).

As cultivares de amoreira-preta apresentam variação no número e comprimento de raízes, pois demonstram ser influenciáveis pelos fatores de enraizamento e crescimento, tendo em vista a concentração de açúcares e hormônios (Vignolo et al., 2014). Uma vez que, o maior comprimento de raiz pode estar associado com a maior concentração endógena de auxinas, que favoreve o desenvolvimento do sistema radicular (Antunes et al., 2000). Foi verificado que, aplicações endógenas de auxina sintética podem alterar a concentração de açúcares na parte aérea e radicular, sendo a auxina sintetizada nas gemas apicais e folhas novas, de onde é conduzida para a base da planta (Dias et al., 2011; Fachinello et al., 2005). Por sua vez, a devisão celular prevalecerá sobre a diferenciação no meristema apical, assim que existir uma maior concentração de auxinas, em proporção a citocininas, durante o crescimento radicular (Moubayidin et al., 2010).

A presença de folhas nas estacas favoreceu o número e o comprimento das raízes, assim como no trabalho de Vignolo et al (2014), não havendo diferenças significativas entre os tipos de estacas e raízes, para o variável número de folhas. Os maiores valores de área foliar foram encontrados na cv. BRS Cainguá, tanto para estacas caulinares, como as de raiz, diferindo significativamente da Tupy $(\mathrm{p}=0,050)$.

A produção de massa fresca de parte aérea de estacas caulinares foi maior que observada nas de estacas de raízes.

Quando realizada a correlação de Pearson para as variáveis MFPA e MSPA, foi obtida uma correlação perfeita e positiva (1) para estas variáveis em estacas caulinares. Havendo assim, a redução do peso e a perfeita secagem do material, o mesmo ocorreu para estacas de raiz. Estes resultados foram encontrados para a cv. Tupy e para a cv. BRS Cainguá.

As observações referentes às variáveis e o tipo de estaca utilizado para a propagação da cultivar BRS Cainguá, 
evidenciam diferenças significativas no CPA e do MFPA, apontando maiores médias em estacas de parte aérea, como pode ser visualizado na Tabela 1.

Ainda, verifica-se que o enraizamento das estacas radiculares foi superior em comparação às estacas caulinares, no entanto porcentagem MFPA foi inferior. O enraizamento em estacas com folhas, antecipado, promove o enraizameno adventicio, assim como a sobrevivência das estacas (Hartmann et al., 2002). Podemos assumir que a presença de folhas nas estacas não influencia diretamente na sobrevivência das mesmas. Mesmo que, as folhas sejam o loco da síntese de auxina e carboidratos, e por isso espera-se que a presença das folhas auxilie no desenvolvimento das raízes. A síntese de compostos fenólicos pela parte aerea é comumente associada ao desenvolvimento de estacas com folhas. Compostos fenólicos como o catecol, o ácido cafeico e o clorogênico, associados a auxinas induzem a iniciação das raízes (Pacheco \& Franco, 2008; Vignolo et al. 2014). O processo de coleta das estacas foi conduzido no inverno, o que geralmente diminui os níveis dos promotores de enraizamento.

O maior grau de lignificação, assim como os baixos níveis de auxina endógena, presentes em algumas estacas caulinares de amoreira-preta, dificultam o enraizamento (Maia \& Botelho, 2008). O que foi observado no presente trabalho, apesar de não ser comparado o tempo da estaca, visto a diferença de valores entre as estacas caulinares e de raiz para ambas as cultivares 'Tupy' e 'BRS Cainguá'.

\section{Conclusão}

A amoreira-preta 'BRS Cainguá' pode ser propagada de forma eficaz tanto por estaca caulinar ou radicular.

A cultivar Tupy tem menor potencial de enraizamento quando comparado a 'BRS Cainguá'.

As estacas radiculares podem ser utilizadas na propagação de amoreira-preta, apresentando maior potencial a ser utilizado quando comparadas com as caulinares.

Com este estudo é possível compreender aspectos da propagação vegetativa da amora-preta, e orientar a pesquisa com mais eficiência, visando o cultivo, comercialização e conservação. Assim, reforçamos a necessidade de estudos sobre a propagação vegetal de cultivares de interesse econômico, bem como uma atenciosa e detalhada condução experimental, tal como é o caso deste trabalho.

\section{Referências}

Andrade, R. A., Martins, A. B. G., Silva M. T. H. \& Turolla I. G. (2007). Propagação da amora-preta por estaquia utilizando ácido indolbutírico. Revista Caatinga, Mossoró, 20 (2), 79-83. file://C:/Users/Usuario/Downloads/315-Artigo\%20de\%20submiss\%C3\%A3o-824-1-10-20070706\%20(3).pdf

Antunes, L. E. C. (2002). Amora-preta: nova opção de cultivo no Brasil. Ciência Rural, 32 (1), 151-158. https://www.scielo.br/pdf/cr/v32n1/a26v32n1.pdf

Antunes, L. E. C., Chalfun, N. N. J. \& Regina M. A. (2000). Propagação de cultivares de amoreira-preta (Rubus spp) através de estacas lenhosas. Revista Brasileira de Fruticultura, Jaboticabal, 22 (2), 195-199.

Antunes, L. E. C., Regina, M. A. \& Filho, J. D. (2002). A cultura da amora-preta. Boletim Técnico, 69, EPAMIG. 28p.

Antunes, L. E. C. \& Raseira, M. C. B. (2004). Aspectos técnicos da cultura da amora-preta. Documentos, 122, Embrapa Clima Temperado, 54 p. https://ainfo.cnptia.embrapa.br/digital/bitstream/item/32426/1/documento-122.pdf

Antunes, L. E. C., Raseira, M. C. B. (2018). Fruticultura: cultivar de amora-preta BRS Cainguá e técnicas de cultivo do mirtilo. In: Wolff LF, Medeiros CAB (Ed.). Alternativas para a diversificação da agricultura familiar de base ecológica. Pelotas: Documentos, 467, Embrapa Clima Temperado, 58-63. https://www.infoteca.cnptia.embrapa.br/infoteca/bitstream/doc/1101084/1/LuisEduardoCorreaDOCUMENTOS467.indd.pdf

Beyl, C. A. \& Trigiano, R. N. (2008). Plant propagation: concepts and laboratory exercises. Boca Raton: CRC. 462 p. Doi: 10.1017 / S0014479708007382

Cruz, C. D. (2013). A software package for analyses in experimental statistics and quantitative genetics. Acta Scientiarum, 35(3), 271-276. 10.4025/actasciagron.v35i3.21251

Dias, J. P. T. \& Ono, E. O. (2010). Produção de mudas de amoreira-preta. Portal Todafruta. Universidade Estadual Paulista “Júlio de Mesquita Filho” - UNESP. Departamento de Horticultura Botucatu-SP. https://www.todafruta.com.br/producao-de-mudas-da-amora-preta/

Dias, J. P. T., Ono, E. O. \& Filho, J. D. (2011). Enraizamento de estacas de brotações oriundas de estacas radiculares de amoreira-preta. Revista Brasileira de Fruticultura, 33(1), 649-653. https://www.scielo.br/pdf/rbf/v33nspe1/a90v33nspe1.pdf

Fachinello, J. C., Hoffmann, A. \& Nachtigal, J. C. (2005). Propagação de plantas frutíferas. Brasília, DF: Embrapa informação tecnológica. 221p. 
Research, Society and Development, v. 10, n. 4, e23910414104, 2021

(CC BY 4.0) | ISSN 2525-3409 | DOI: http://dx.doi.org/10.33448/rsd-v10i4.14104

Franzon, R. C., Carpenedo, S. \& Silva, J. C. S. (2010). Produção de mudas: Principais técnicas utilizadas na propagação de fruteiras. Documento, 283, Embrapa Cerrados. 56p. https://ainfo.cnptia.embrapa.br/digital/bitstream/item/77778/1/doc-283.pdf

Hartmann, H. T. \& Kester, D. E. (2002). Plant propagation: principles and pratices. (7a ed.), Prentice-Hall.880p.

Maia, A. J. \& Botelho, R. V. (2008). Reguladores vegetais no enraizamento de estacas lenhosas de amoreira-preta cv. Xavante. Semina, 29 (2), $323-330$. $10.5433 / 1679-0359.2008 v 29 \mathrm{n} 2 \mathrm{p} 323$

Moubayidin, L., Perilli, S., Dello Loio, S., Di Mambro, R., Constantino, P. \& Sabatini, S. (2010). The rate of cell differentiation controls the arabidopsis root meristem growth phase. Current Biology, 20 (12), 1138-1143.https://doi.org/10.1016/j.cub.2010.05.035

Pacheco, J. P. \& Franco, E. T. H. (2008). Substratos e estacas com e sem folhas no enraizamento de Luehea divaricata Mart. Ciência Rural, Santa Maria, 38(7), 1900-1906. https://www.scielo.br/pdf/cr/v38n7/a15v38n7.pdf

Raseira, M. C. B., Franzon, R. C., Feldberg, N. P., Antunes, L. E. C., Scaranari, C. (2020). 'BRS Cainguá', a blackberry fresh-market cultivar. Crop breeding and applied Biotechnology, 20(1), 1-3. http://dx.doi.org/10.1590/1984-70332020v20n1c4

Vignolo, G. K., Picolotto, L., Gonçalves, M. A., Pereira, I. S. \& Antunes, L. E. C. (2014). Presença de folhas no enraizamento de estacas de amoreira-preta. Ciência Rural, Santa Maria, 44(3), 467-472. http://dx.doi.org/10.1590/S0103-84782014000300013.

Yamamoto, L. Y., Koyama, R., Borges, W. F. S., Antunes, L. E. C., Assis, A. M. \& Roberto, S. R. (2013). Substratos no enraizamento de estacas herbáceas de amora-preta Xavante. Ciência Rural, 43(1), 15- 20. https://doi.org/10.1590/S0103-84782012005000135 